\title{
Design and Calculation for Test Tube with the Aim of Regulation Simultaneous Crystallization Tests
}

\author{
Aco Janicijevic $^{1}$, Nebojsa Danilovic ${ }^{2}$, Branislav Cabric ${ }^{2 *}$ \\ ${ }^{1}$ Faculty of Technology and Metallurgy, University of Belgrade, Belgrade, Serbia; ${ }^{2}$ Faculty of Sciences, University of Kragujevac, \\ Kragujevac, Serbia. \\ Email: *branko.cabric@gmail.com
}

Received May $7^{\text {th }}, 2012$; revised June $11^{\text {th }}, 2012$; accepted June $19^{\text {th }}, 2012$

\begin{abstract}
A design for an air-cooled test tube, with a series of modular and movable rings (cylindrical "crystallization comb"), installed in a laboratory crucible furnace is presented. The setup allows easy regulation simultaneous crystallization tests of a series of different crystallization rates in several columns (matrix) of test tubes, enabling fast studies of obtaining crystals. This low-budget, portable device (i.e. adjustable airstream with more simple control options), can also be applied in tube and chamber furnaces. The relations between the crystallization rate and parameters of air-cooled test tube are given and numerically analyzed.
\end{abstract}

Keywords: Technique for Crystal Growth; Design and Calculation; Test Tube-Cylindrical Crystallization Combs; Crystallization Clusters - Obtaining Crystals from Melt

In a previous paper [1] we have described a design for air-cooled test tube (bilateral "crystallization comb"), installed in a laboratory chamber furnace with the aim of regulating the crystallization fronts and rates in a two columns of crucibles. In this paper, we describe the development and improvement of the exterior of the cooler, i.e. modular air-cooled test tube (cylindrical "crystallization comb") with several columns of test tubes ("crystallization cluster") (Figure 1), and a numerical study of control options of matrix of new crystallization parameters (Figures $\mathbf{2}$ and $\mathbf{3}$ ). The improved cooler is simpler to build and handle, features regulation of different crystallization fronts and rates in several columns of test tubes [with the help of telescopic movable tube/sieve - see (5) in Figure 1(a)] or rings-see (9) in Figure 1(b)]. This stationary and adaptive device, with operating body air (gas), allows easy regulation simultaneous crystallization tests of different crystallization parameters and substances, enabling fast studies of obtaining single crystals from substances with unknown crystallization parameters, using a laboratory furnaces.

By the assumption that the liberated latent heat of solidification is equal to the heat removed by the air stream through the cooler, the following expression for the matrix of crystallization rates $R_{i j}$ in the test tubes (see Figure 1(b)) is derived [4]:

\footnotetext{
*Corresponding author.
}

$$
R_{i j}=\frac{\Delta T_{j}}{\lambda_{c} \rho_{c}\left(1 / \alpha_{i}+\delta_{j} / k_{j}+\delta_{c} / k_{c}\right)}
$$

where $i$ and $j$ denote the indices of internal rings and external rings/plugs, $c$ is the crystallization substance index, $\Delta T$ denotes the difference between the temperature of the melt and that of the air stream, $\lambda$ is the latent heat of solidification, $\rho$ designates the crystal density, $\alpha$ is the coefficient of heat transfer from the cooler wall to the air stream, $k$ designates the heat conductivity.

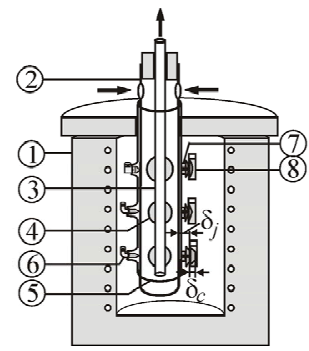

(a)

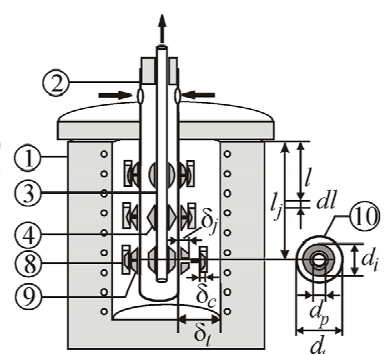

(b)
Figure 1. Air-cooled test tube (cylindrical "crystallization comb") in a crucible furnace: (1) laboratory crucible furnace, (2) air-cooled test tube (cylindrical "crystallization comb"), (3) pipe ("draining shuttle"), (4) modular and movable rings, (5) telescopic movable tube with mounting holes (crystallization test sieve), (6) curved Tamman test tubes [2,3] ("crystallization tests comb"), (7) mounting plugs, (8) test tubes ("crystallization cluster"), (9) rings with radial mounting holes ("junction rings"), and (10) cross section of the air-cooled test tube. 
The coefficient of heat transfer from the test tube wall to the air stream can be calculated using the following expression (p. 152 of [5]):

$$
\alpha_{i}=\left[4.13+0.23\left(\frac{\theta}{100}\right)\right] \frac{w_{i 0}^{0.75}}{d_{t}^{0.25}}
$$

where $\theta$ is average temperature of the airstream in ${ }^{\circ} \mathrm{C}$ (up to $1000^{\circ} \mathrm{C}$ ), and

$$
w_{i 0}=w_{i} \frac{273}{273+\theta}
$$

where $w_{i}$ is average velocity of the airstream next to the ring $i\left(0^{\circ} \mathrm{C}, 1.013\right.$ bar $)$ in $\mathrm{m} / \mathrm{s}$.

On the basis of the continuity and the cross section of the airstream, the following expression for the velocity of the airstream next to the ring $i, \mathrm{w}_{i}$, we obtain:

$$
w_{i}=w_{t}\left(\frac{d_{t}^{2}-d_{p}^{2}}{d_{t}^{2}-d_{i}^{2}}\right)
$$

where $w_{t}$ denotes an average velocity of the airstream in the test tube without ring, $d_{t}$ and $d_{p}$ is the diameter of the test tube and the pipe respectively, $d_{i}$ is diameter of the ring - see (10) in Figure 1(b).

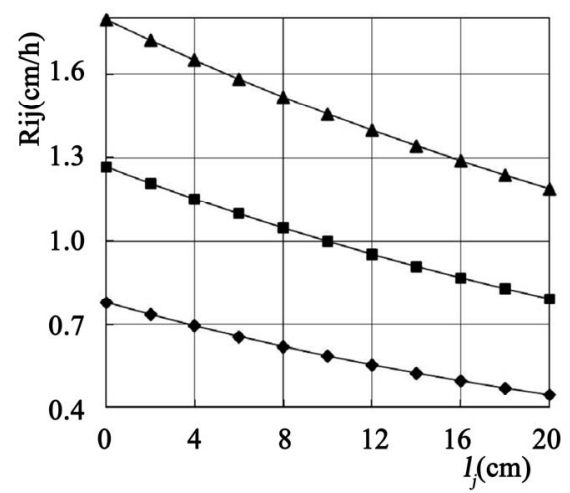

(a)

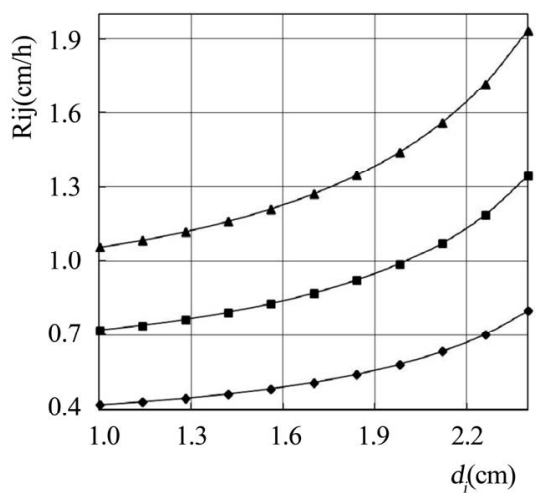

(b)

Figure 2. Crystallization rate $R_{i j}$ as a function of the position of the ring along the test tube, $l_{j}$, and the diameter of the ring, $d_{i}$, when $\Delta T_{0}=150^{\circ} \mathrm{C}:-\downarrow-w_{t}=0.6 \mathrm{~m} / \mathrm{s} ;-\square-w_{t}=1.2$ $\mathrm{m} / \mathrm{s},-\Delta-w_{t}=2 \mathrm{~m} / \mathrm{s}$. (a) $d_{i}=2 \mathrm{~cm}$; (b) $l_{j}=10 \mathrm{~cm}$.
Based on the fact that the heat removed from the test tube wall is equal to the heat accepted by the air stream, we have derived the following expression (integral equation) for the difference between the temperature of the melt and that of the air stream $\Delta T_{j}$ at the point $l_{j}$ :

$$
\Delta T_{j}=\Delta T_{0}-\frac{4}{w_{t} d_{t} \rho_{a} c_{a}} \int_{0}^{l_{j}} \alpha_{t} \Delta T_{l} d l
$$

where $\Delta T_{0}$ denotes the difference between the temperature of the melt and that of the air stream at the point $l_{j}=$ 0, (Figure 1(b)), $\alpha_{t}$ is the coefficient of heat transfer from the test tube without ring to the air stream [Equations (2) and (3) when $d_{i}=d_{p}$ ], $\Delta T_{l}$ denotes the difference between the temperature of the melt and that of the air stream at the point $l, \rho_{a}$ and $c_{a}$ designates density and heat capacity of the air stream, respectively.

In accordance with Equations (1)-(4), the authors obtained the numerical values of crystallization rate, $R_{i j}$, as function of $l_{j}$ and $d_{i}$ (Figure 2), and $w_{t}$ and $\Delta T_{0}$ (Figure 3),

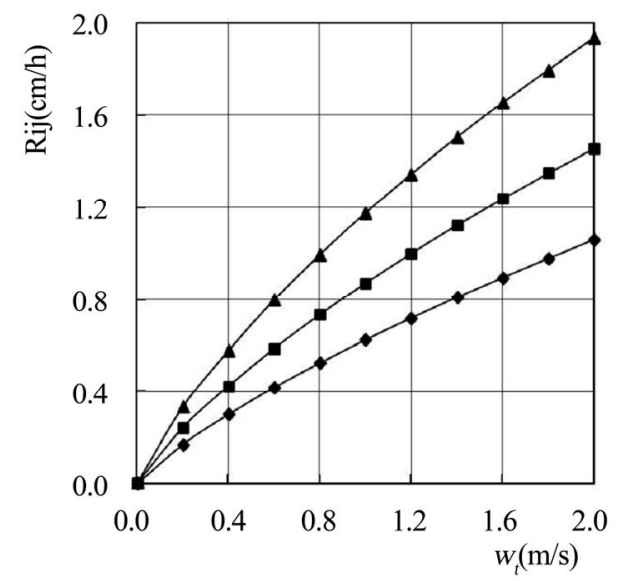

(a)

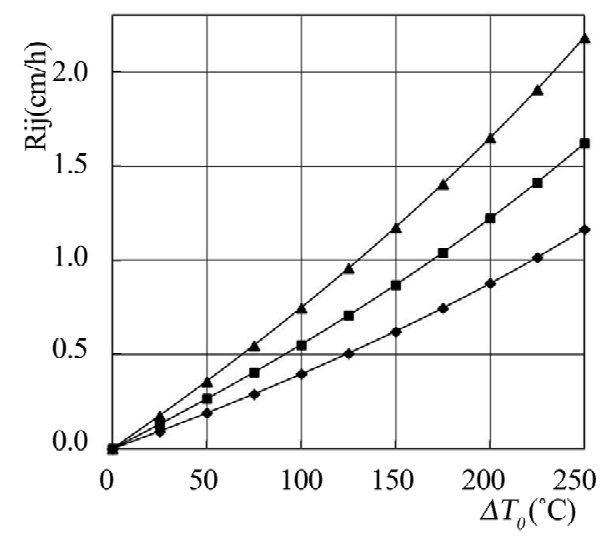

(b)

Figure 3. Crystallization rate $R_{i j}$ as a function of the velocity of the airstream in the test tube, $w_{t}$, and difference between the temperature of the melt and that of the air stream at the point $l=0-\Delta T_{0}$, when $l_{j}=10 \mathrm{~cm}:-d_{i}=1 \mathrm{~cm},-\square-d_{i}=2$ $\mathrm{cm},-\Delta-d_{i}=2.4 \mathrm{~cm}$. (a) $T_{0}=150^{\circ} \mathrm{C}$; (b) $w_{t}=1 \mathrm{~m} / \mathrm{s}$. 
in the case of bismuth: $T_{m e l t}=271^{\circ} \mathrm{C}, \lambda_{c}=52300 \mathrm{~J} / \mathrm{kg}, \rho_{c}$ $=9800 \mathrm{~kg} / \mathrm{m}^{3}$ and $k_{c}=7.2 \mathrm{~W} / \mathrm{mK}$. In all numerical calculation is taken that: $d_{t}=3 \mathrm{~cm}, d_{p}=1 \mathrm{~cm}, \delta_{j}=0.5 \mathrm{~cm}, k_{j}$ $=0.756 \mathrm{~W} / \mathrm{mK}$ (pyrex i.e. borosilicate glass, softening point $\approx 600^{\circ} \mathrm{C}$ ), $\delta_{c}=0 \mathrm{~cm}$ (Figure 1(b)), $\rho_{a}=0.682$ $\mathrm{kg} / \mathrm{m}^{3}$ and $c_{a}=1.035 \mathrm{~kJ} / \mathrm{kgK}$.

The shape of crystallization front in each test tube can be regulated by the plug or ring front (Figure 1). The crystallization rate in each test tube can be regulated by the position of the ring along the test tube (Figure 2(a)) and by the diameter of the ring (Figure 2(b)); and/or by the velocity of the air stream and the difference between the temperature of the melt and that of the air stream at the point $l_{j}=0$-Figures 3(a) and (b), respectively. The crystallization rate in tests tubes can also be regulated by the thickness of the ring $\delta_{j}$ (Equation (1)). Different crystallization rates in the test tubes in one ring ("wreath") can be simultaneous tested using asymmetric ring. The temperature gradient is regulated by the distance aircooled test tube from the furnace wall $\delta_{t}$. Different temperature gradients in the test tubes in one ring can be simultaneous tested using air-cooled test tube dislocation to the axis of the furnace, i.e. asymmetric position of the key.

Tamman test tubes (Figure 3.1.-8 of [2]; Figure 3.1-2. of [3]), plugs and rings of various numbers, shapes and dimensions can be mounted and thus simultaneously tested (fineness of the comb). By varying the internal and external shapes and dimensions of the cooler, a set of "crystallization combs/keys" can be modeled for tests over a different range of crystallization fronts and rate intervals. The air cooled test tube can be installed into a tube furnace in a horizontal position ("crystallization
shelf"-Figures 16 and 17 in [6]) or vertical position ("crystallization corncob"-Figure 13 in [6]). Several different air-cooled test tubes (a family group of "crystallization keys/combs") can be installed in the chamber furnace (Figure 11 in [6]. This increases the number of simultaneous crystallization tests (comb) of different crystallization parameters, using a low-budget, modular, easy to install and remove, portable ("pocket") device, i.e. airstream with more simple control options. This provides a way ("crystallization cluster") for fast studies of obtaining crystals from substances with unknown crystallization parameters, and the economic expansion application of laboratory furnaces.

\section{REFERENCES}

[1] B. Cabric and N. Danilovic, "Test Tube for Obtaining Crystals," Journal of Applied Crystallography, Vol. 42, 2009, p. 1205. doi:10.1107/S0021889809036188

[2] K.-Th. Wilke and J. Bohm, "Kristallzüchtung," Verlag Harri Deutsch, Frankfurt, 1988.

[3] K.-T. Vilke, "Virashchivanie Kristallov," Nedra Leningradskoe odelenie, Leningrad, 1977.

[4] B. Cabric, N. Danilovic and A. Janicijevic, "Tube for Obtaining Crystals in a Laboratory Furnaces," Instruments and Experimental Techniques, Vol. 54, No. 2, 2011, pp. 282-283.

[5] E.-R. Schramek, "Taschenbuch für Heizung + Klimatechnik," Oldenbourg Industrieverlag GmbH, München, 2007.

[6] A. Janćijević and B. Čabrić, "New Class of Apparatus for Crystal Growth from Melt," In: N. Kolesnikov and E. Borisenko, Eds., Modern Aspects of Bulk Crystal and Thin Film Preparation, InTech-Open Access Publisher, Rijeka, 2012, pp. 3-24. 